\title{
ЕКСПЕРИМЕНТАЛЬНЕ ДОСЛІДЖЕННЯ СТОКУ З ВОДОПРОНИКНОГО БЕТОННОГО ПОКРИТТЯ ДЛЯ ВИСОКОІНТЕНСИВНИХ ДОЩІВ МАЛОЇ ТРИВАЛОСТІ
}

\begin{abstract}
Використання водопроникних удосконалених покриттів (ВУП) - ефективний метод управління дощовим стоком на урбанізованих територіях. Основним гідравлічним параметром під час моделювання систем дощового водовідведення є гідрографи стоку для дощів розрахункової тривалості та інтенсивності. Регулювання дощового стоку за допомогою ВУП на сьогодні достатньо добре вивчене, проте все ще $\epsilon$ нез'ясовані питання щодо функції "дощові опади - стік", особливо для короткотривалих дощів високої інтенсивності. Виконано серію експериментальних досліджень дощового стоку з фрагмента натурного ВУП на підставі пористого бетону. Використано типову конструкцію ВУП з нижнім шаром зі щебеню товщиною 220 мм та верхнім шаром із водопроникного бетону товщиною 100 мм. Розміри дослідного ВУП - 3,0×0,3×0,32 м, поздовжній похил покриття - 0,01. Регулювальні властивості ВУП отримано для модельних дощів особливо високої інтенсивності 10300 л/(с·га) з тривалістю від 15 с до 60 с. Дощ тривалістю $t_{\text {con.0 }}=38,4$ с відповідає часу поверхневої концентрації для аналогічного повністю водонепроникного асфальтового покриття. З'ясовано, що використання ВУП зменшує у такому випадку максимальну витрату стоку в 3,1 раза - від 0,927 л/с до 0,302 л/с, тоді як час досягнення максимальної витрати зростає на $20,3 \%$. Час концентрації стоку $t_{\text {con.вУП }}=112,0$ с 3 дослідженого ВУП у 2,92 раза більший порівняно 3 аналогічним водонепроникним басейном.
\end{abstract}

Ключові слова: водопроникні удосконалені покриття; водопроникний бетон; гідрограф стоку; максимальна витрата стоку; час концентрації.

Вступ. Інтенсивна розбудова міст та збільшення площ водонепроникних територій призводить до значного зростання об'ємів та максимальних витрат поверхневого стоку. Затримання у часі та зменшення пікових витрат дощових стічних вод залишається ключовою задачею регулювання дощового стоку, спрямованою як на зменшення збитків від затоплення територій під час сильних злив, так і на захист довкілля від негативного впливу забрудненого поверхневого стоку. На сьогодні розроблено цілу низку методів, спрямованих на вирішення цієї проблеми. В умовах щільної міської забудови одним з найефективніших методів регулювання дощового стоку є використання водопроникних удосконалених покриттів (ВУП) (Pilon et al., 2019; Tkachuk \& Zhuk, 2012; Zhuk et al., 2018).

Аналіз останніх досліджень та публікацій. Як верхній шар ВУП використовують пористий асфальт чи бетон, пористу бруківку чи блоки, газонні решітки та iн. (Lin et al., 2014). Використання ВУП дає змогу зменшити об'єм поверхневого стоку мінімум на $40 \%$, забезпечує його часткове очищення, сприяє поповненню запасів грунтових вод, а також зниженню рівня шуму на дорогах (Alsubih et al., 2016; Liu et al., 2018; Luo et al., 2018; Pilon et al., 2019).

Пористий водопроникний бетон виготовляють 3 цементу, заповнювача та води, частково або повністю виключаючи дрібний заповнювач - пісок. Розмір грубого заповнювача, водо-цементне відношення (В/Ц) та співвідношення цемент - заповнювач (Ц/3) визначають механічні характеристики пористого бетону. Механічні характеристики дають змогу влаштовувати ВУП не тільки в пішохідних зонах, але й на автостоянках, паркових доріжках та автодорогах із невисоким рівнем навантаження (Ali et al., 2014; Luo et al., 2018; Ngohpok et al., 2018; Pilon et al., 2019).

Гідравлічні дослідження підтверджують високий рівень водопроникності пористих бетонів. Значення коефіцієнта фільтрації, залежно від пористості матеріалу, розмірів заповнювача, густини та інших кількісних та якісних характеристик бетону, змінюється в межах 123 мм/c (Ali et al., 2014; Bean et al., 2007; Liu et al., 2018; Luo et al., 2018). Накопичення дощового стоку на поверхні ВУП можливе лише у випадках дуже коротких притоків високої інтенсивності (Zhuk \& Kachmar, 2015).

\section{Інформація про авторів:}

Жук Володимир Михайлович, канд. техн. наук, доцент, кафедра гідравліки та сантехніки. Email: zhuk_vm@ukr.net; https://orcid.org/0000-0002-2275-0799

Качмар Ірина Зіновіївна, аспірант, кафедра гідравліки та сантехніки. Email: irynka.shevchuk@gmail.com; https://orcid.org/0000-0001-9659-4357

Фасуляк Вадим Євгенійович, студент, кафедра гідравліки та сантехніки. Email: vadim.fasulyak@gmail.com; https://orcid.org/0000-0002-8734-0387

Цитування за ДСТУ: Жук В. М., Качмар І. З., Фасуляк В. Є. Експериментальне дослідження стоку з водопроникного бетонного покриття для високоінтенсивних дощів малої тривалості. Науковий вісник НлтУ України. 2019, т. 29, № 9. С. 132-135.

Citation APA: Zhuk, V. M., Kachmar, I. Z., \& Fasuliak, V. Ye. (2019). Experimental study of the outflow from a pervious concrete system for short-term rainfalls of high intensity. Scientific Bulletin of UNFU, 29(9), 132-135. https://doi.org/10.36930/40290923 
Регулювання дощового стоку за допомогою ВУП це достатньо глибоко вивчена на сьогодні проблема (Alyaseri \& Zhou, 2015; Turco et al., 2017). Водночас все ще залишаються невирішеними питання стосовно взаємозв'язків "дощові опади - поверхневий стік", особливо для короткотермінових злив високої інтенсивності.

Об'єктом дослідження є дощовий стік з ВУП із верхнім водопроникним шаром на основі пористого бетону.

Предметом дослідження є гідрографи дощового стоку та їхні основні характеристики - час концентрації та максимальна витрата стоку.

Метою роботи є експериментальне дослідження регулювальних властивостей фрагменту натурного ВУП на підставі водопроникного бетону для високоінтенсивних злив малої тривалості.

Для реалізації мети було вирішено такі основні завдання дослідження:

- сплановано натурний фізичний експеримент, спроектовано та змонтовано експериментальну установку - фрагмент натурного ВУП з верхнім шаром, виконаним з пористого водопроникного бетону;

- виконано серію експериментальних досліджень дощового стоку з ВУП для притоку із інтенсивністю 10300 л/(с-га) та тривалістю 15-60 с з отриманням експериментальних характеристик стоку в режимі онлайн;

- виконано математичне оброблення та узагальнення експериментальних результатів 3 отриманням основних водорегулювальних характеристик дослідженого ВУП.

Матеріали та методи дослідження. У роботі використано експериментальний метод гідравлічних досліджень 3 подальшим статистичним обробленням отриманих результатів.

Досліджувана система ВУП з габаритними розмірами $3,0 \times 0,30 \times 0,32$ м змонтована у дослідному гідравлічному лотку лабораторії гідравліки Національного університету "Львівська політехніка". Експериментальна установка модельного басейна стоку з ВУП складається 3 розподільного трубопроводу 1 ; збірного лотка 5, завантаженого системою водопроникного вдосконаленого покриття 2-4; приймального резервуара 6; електронної ваги 7 марки AXIS BDU-60; цифрового інтерфейсу RS-232 8 та персонального комп'ютера 9 (рис. 1).

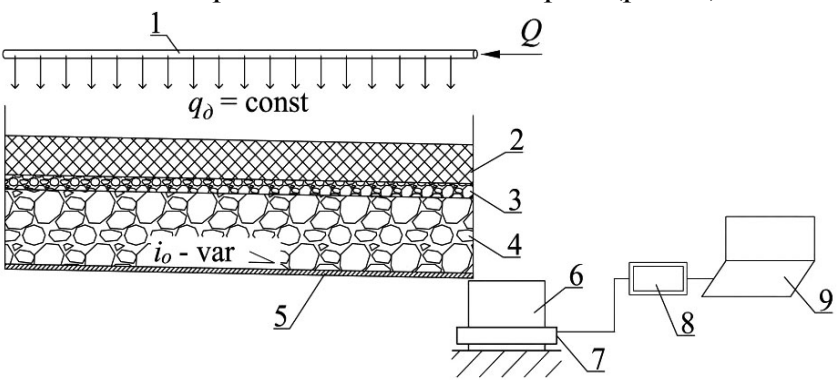

Рис. 1. Схема експериментальної установки: 1) розподільний трубопровід; 2) водопроникний бетон; 3) вирівнювальний шар; 4) основа з грубого щебеню; 5) збірний лоток; 6) приймальний резервуар; 7) електронна вага AXIS BDU-60; 8) цифровий вихід RS-232; 9) персональний комп'ютер

Розподільний трубопровід 1 виготовлено $з$ поліпропіленової труби марки PP-R $32 \times 4,4$ довжиною 3 м, у якій 3 кроком 5 см зроблено отвори діаметром 2 мм. Така конструкція трубопроводу дає змогу імітувати дощі постійної в часі інтенсивності по всій площі модельного басейна стоку. Після фільтрації крізь конструкцію ВУП вода по збірному лотку 5 стікала у приймальний резервуар 6. Збірний лоток 5 шириною 300 мм - стале- вий, з бічними стінками 3 листового скла. У лоток 5 було укладено накопичувально-регулювальний шар 4 зі щебеню фракцією 20-40 мм товщиною 200 мм, вирівнювальний шар 3 зі щебеню фракцією 10-20 мм товщиною 20 мм та плити 3 водопроникного бетону 2 товщиною 100 мм. Загальна висота ВУП - $H=320$ мм, площа модельного басейна стоку $-F_{\text {бас }}=0,9 \mathrm{M}^{2}$.

Приймальний резервуар 6 має такі габарити 700·400·280 мм, а його повний об'єм - 78,4 дм³ . Електронна вага 7, на яку встановлювали приймальний резервуар 6, дає можливість вимірювати масу рідини з похибкою \pm 10 г. Через цифровий інтерфейс 8 вага з'єднана 3 персональним комп'ютером 9. Це дало змогу в режимі реального часу отримувати значення маси притоку через кожні 0,125 с у вигляді файлу даних формату txt.

Враховуючи густину води за температури досліджень $T=20{ }^{\circ} \mathrm{C}\left(\rho=998,2\right.$ кг $\left./ \mathrm{m}^{3}\right)$, отримували часову залежність об'єму поверхневого стоку з ВУП $W(t)$. Чисельним диференціюванням функції $W(t)$ отримали значення об'ємної витрати стоку $Q(t)$ в різні моменти часу. Використали двоточкову схему з рівновіддаленими значеннями аргументу, згідно з якою об'ємна витрата в момент часу $t_{j}$ :

$$
Q_{j}=\frac{W_{j+1}-W_{j-1}}{2 \Delta t}, j=\overline{1, n},
$$

де: $W_{j+1}, W_{j-1}-$ об'єми стоку з ВУП відповідно в моменти часу $t_{j+1}$ та $t_{j-1} ; \Delta t-$ крок аргументу; прийнято $\Delta t$ $=3 \mathrm{c}$.

Результати дослідження. Серію експериментальних досліджень дощового стоку з ВУП виконано для притоку з інтенсивністю $q_{\partial}=10300$ л/(с·га) та тривалістю $t_{\partial}=15-60$ с за постійного значення поздовжнього похилу басейна стоку $i_{0}=0,01$.

Отримано експериментальні гідрографи стоку з досліджуваного ВУП. Для жодного 3 модельних дощів не спостерігали накопичення стоку на поверхні ВУП, що є очевидним за інтенсивності дощу $i_{\partial}=1,03$ мм/с та середнього значення коефіцієнта фільтрації водопроникного пористого бетону $k_{\phi}=12 \mathrm{~mm} / \mathrm{c}$.

Для визначення кількісних значень регулювальних характеристик ВУП гідрографи стоку, отримані з натурного ВУП на підставі пористого бетону, порівняно 3 гідрографами стоку для аналогічного водонепроникного басейна стоку. За характерну тривалість дощу прийнято час концентрації стоку з аналогічного водонепроникного плоского лінійного в плані басейна стоку, який визначено за модифікованим методом кінематичної хвилі (Tkachuk \& Zhuk, 2012):

$$
t_{\text {con }}=\frac{5}{3}\left(\psi_{\text {mid }} q_{\partial}\right)^{-0,4} \cdot n_{1}^{0,4} \cdot i_{0}^{-0,3} \cdot L^{0,6},
$$

де: $\psi_{\text {mid }}-$ коефіцієнт стоку; $n_{1}-$ коефіцієнт шорсткості водонепроникного покриття; прийнято $n_{1}=0,016$, як для крупнозернистого асфальтового покриття (Chow, Maidment \& Mays, 1988). Для $\psi_{\text {mid }}=1 ; q_{\partial}=1,03 \times 10^{-3} \mathrm{M} / \mathrm{c}$; $L=3 \mathrm{м} ; i_{0}=0,01$ та $n_{1}=0,016$ час концентрації поверхневого стоку 3 аналогічного асфальтового покриття $t_{\text {con }}=38,4 \mathrm{c}$.

Витрата дощових стічних вод з лінійних у плані басейнів стоку для дощу тривалістю $t_{\partial}=t_{c o n}$ на першому етапі гідрографа стоку (за $t \leq t_{c o n}$ ) (Tkachuk \& Zhuk, 2012):

$$
Q_{1}=Q_{r} \cdot\left(t / t_{\text {con }}\right)^{5 / 3},
$$

тоді як на другому етапі гідрографа (за $t_{c o n}<t \leq 2 t_{c o n}$ ): 


$$
Q_{2}=Q_{r}\left[1-\left(\frac{t-t_{c o n}}{t_{c o n}}\right)^{5 / 3}\right],
$$

де $Q_{r}$ - розрахункова (максимальна секундна) витрата дощового стоку.

Максимальна експериментальна витрата 3 ВУП за $t_{\partial}=t_{c o n}\left(Q_{\max }=0,302 \pi / \mathrm{c}\right)$ у 3,1 раза менша за максимальну розрахункову витрату $Q_{r}=Q_{\partial}=0,927$ л/с, тоді як час досягнення максимальної витрати під час використання ВУП $-t_{\max }=46,2$ с, що на $20,3 \%$ більше порівняно 3 аналогічним повністю водонепроникним басейном стоку без регулювання дощового стоку (рис. 2).

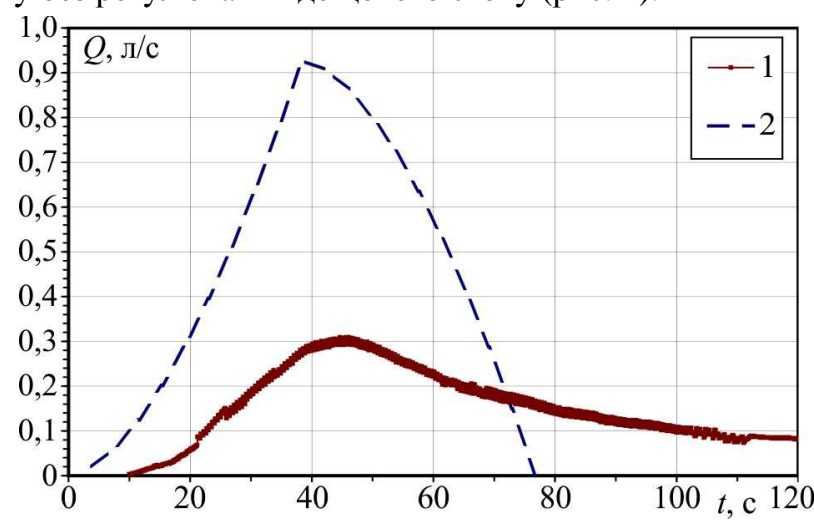

Рис. 2. Гідрографи притоку: 1) експериментальний, з ВУП; 2) теоретичний, без ВУП ( $q_{д}=10300$ л/(с·га); $t_{д}=38,4$ c; L=3 м; $\left.\mathrm{i}_{0}=0,01\right)$

Залежність часу $t_{\max }$, при якому витрата стоку 3 досліджуваного ВУП є максимальною, від тривалості дощу відображено на рис. 3. Цю залежність для дощів тривалістю $0<t_{\partial} \leq t_{p}$ можна описати рівнянням

$$
t_{\max }=27,5(\exp )^{0,013 t_{\partial}}
$$

де $t_{p}-$ рівноважна тривалість дощу, при якій $t_{\text {max }}=t_{\partial}$.

За інтенсивності $q_{\partial}=10300$ л/(с·га) для дослідженого ВУП значення рівноважної тривалості дощу дорівнює $t_{p}=60,0$ с. Для дощів 3 інтенсивністю $q_{\partial}=10300$ л/(с·га) та тривалістю $t_{p}>60,0$ с, ефекту затримки в часі максимальної витрати під час використання ВУП вже не спостерігаємо, тобто $t_{\max }=t_{\partial}$, як $\mathrm{i}$ для звичайних водонепроникних поверхонь.

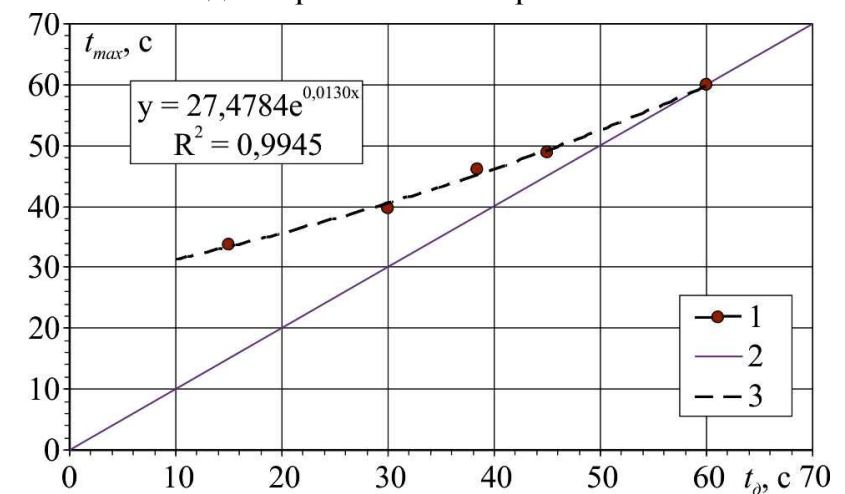

Рис. 3. Залежність між тривалістю модельного дощу та часом досягнення максимальної витрати стоку з ВУП: 1) експериментальні результати; 2) лінійна асимптота $t_{\max }=t_{\partial}$; 3) апроксимація експериментальних результатів (4)

Водночас при $t_{\partial}=t_{p}=60,0$ с значення максимально можливої розрахункової витрати стоку 3 ВУП $Q_{r}$ $=0,927$ л/с все ще не досягнуто (рис. 4). Для умов дослідження отримано лінійну залежність між максимальною витратою стоку з ВУП та тривалістю експериментального дощу:

$$
Q_{\max }=0,0083 t_{\partial} \text {. }
$$

Екстраполяцією залежності (5) до максимальної розрахункової витрати $Q_{r}=0,927$ л/с отримано час концен-

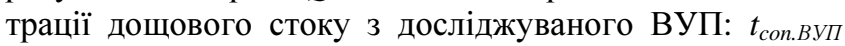
$=112$ с. Для дощів заданої інтенсивності за їх тривалості понад 112 с максимальна витрата стоку з ВУП вже не зростає і дорівнює $Q_{r}=Q_{\partial}$. Отже, порівняно з використанням звичайних водонепроникних покриттів час досягнення максимальної витрати під час застосування дослідженого ВУП на підставі водопроникного пористого бетону зростає у $t_{\text {con.вуП }} / t_{\text {con }}=2,92$ раза.

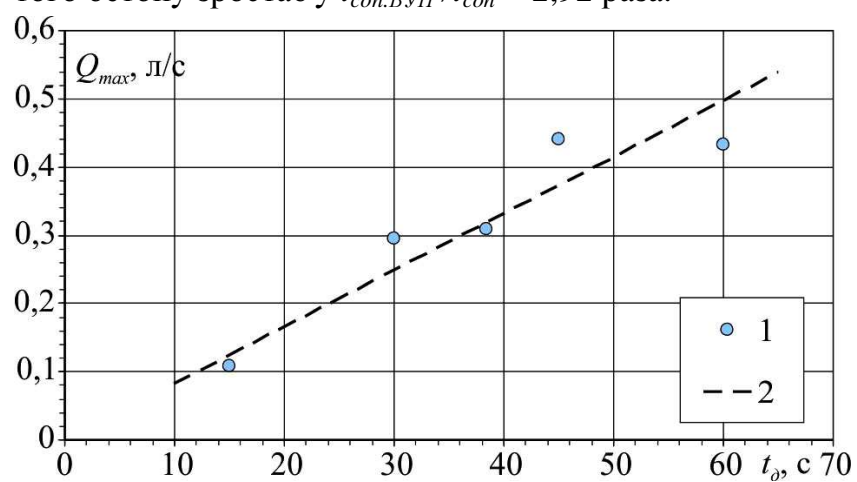

Рис. 4. Залежність максимальної витрати дощового стоку з ВУП від тривалості дощу: 1) експериментальні результати; 2) лінійна апроксимація (5) $\left(q_{\partial}=10300 \mathrm{л} /(\mathrm{c} \cdot \Gamma \mathrm{a}) ; L=3 \mathrm{~m} ; i_{0}=0,01\right)$

Висновки. Підтверджено ефективність використання водопроникних удосконалених покриттів для комплексного регулювання поверхневого стоку з урбанізованих територій для високоінтенсивних злив малої тривалості. Експериментальні дослідження дощового стоку 3 фрагмента натурного ВУП на підставі пористого водопроникного бетону показали, що використання ВУП дає змогу зменшити максимальну витрату стоку у 3,1 раза та збільшити час концентрації поверхневого стоку у 2,92 раза порівняно з використанням аналогічних водонепроникних поверхонь.

\section{References}

Ali, M. K., \& Kareem, Q. M. Sh. (2014). Experimental study on mechanical and hydrological properties of pervious concrete with different water cement ratio. International Journal of Enhanced Research in Science Technology \& Engineering, 3(12), 107-113.

Alsubih, M., Arthur, S., Wright, G., \& Allen, D. (2016). Experimental Study on the hydrological performance of a permeable pavement. Urban Water Journal, 14(4), 427-434. https://doi.org/10.1080/1573062X.2016.1176221

Alyaseri, I., \& Zhou, J. (2015). Comparative evaluation of different types of permeable pavement for stormwater reduction-St. Louis green alley pilot study. International Low Impact Development Conference, (pp. 274-284). https://doi.org/10.1061/9780784479025.028

Bean, E. Z., Hunt, W. F., \& Bidelspach, D. A. (2007). Field survey of permeable pavement surface infiltration rates. Journal of Irrigation and Drainage Engineering, 133(3), 249-255. https://doi.org/10.1061/(ASCE)0733-9437(2007)133:3(249)

Chow, V. T., Maidment, D. R., \& Mays, L. W. (1988). Applied Hydrology. McGraw Hill, New York, 572 p.

Lin, W., Ryu, S. W., \& Cho, Y. (2014). A case study of flow characteristics of permeable pavements by time and space model. Can. J. Civ. Eng., 41, 660-666. https://doi.org/10.1139/cjce-2013$\underline{0165}$

Liu, R., Liu, H., Sha, F., Yang, H., Zhang, Q., Shi, S., \& Zheng, Z. (2018). Investigation of the porosity distribution, permeability, and mechanical performance of pervious concretes. Journal Processes, 6(78), 1-14. https://doi.org/10.3390/pr6070078 
Luo, G., Wei, H., \& Han, Y. (2018). Strength, permeability, and freeze-thaw durability of pervious concrete with different aggregate sizes, porosities, and water-binder ratios. Applied Sciences, 8(1217), 1-16. https://doi.org/10.3390/app8081217

Ngohpok, C., Sata, V., Satiennam, Th., Klungboonkrong, P., \& Chindaprasirt, P. (2018). Mechanical properties, thermal conductivity, and sound absorption of pervious concrete containing recycled concrete and bottom ash aggregates. KSCE Journal of Civil Engineering, 22(4), 1369-1376. https://doi.org/10.1007/s12205-017-0144-6

Pilon, B. S., Tyner, J. S., \& Yoder, D. C. (2019). The effect of pervious concrete on water quality parameters: A case study. Water, 11(263), 1-10. https://doi.org/10.3390/w11020263

Tkachuk, S. H., \& Zhuk, V. M. (2012). Rehuliuvannia doshchovoho stoku v systemakh vodovidvedennia. Lviv: Publishing house of Lviv Polytetechnic, 216 p. [In Ukrainian].
Turco, M., Kodešová, R., Brunetti, G., Nikodem, A., Fér, M., \& Piro, P. (2017). Unsaturated hydraulic behaviour of a permeable pavement: Laboratory investigation and numerical analysis by using the HYDRUS-2D model. Journal of Hydrology, 554, 780 791. https://doi.org/10.1016/j.jhydrol.2017.10.005

Zhuk, V. M., \& Kachmar, I. Z. (2015). Teoretychnyi rozrakhunok nakopychennia doshchovoho stoku na poverkhni vodopronyknykh udoskonalenykh pokryttiv. (Ser. Construction theory and practice). Bulletin of the National University of Lviv Polytechnic, 823, 122128. [In Ukrainian].

Zhuk, V. M., Vovk, L. I., Matlai, I. I., \& Popadiuk, I. Yu. (2018). Correlation between the total and effective imperviousness in stormwater modelling. Scientific Bulletin of UNFU, 28(10), 92-95. https://doi.org/10.15421/40281019

V. M. Zhuk, I. Z. Kachmar, V. Ye. Fasuliak

Lviv Polytechnic National University, Lviv, Ukraine

\section{EXPERIMENTAL STUDY OF THE OUTFLOW FROM A PERVIOUS CONCRETE SYSTEM FOR SHORT-TERM RAINFALLS OF HIGH INTENSITY}

Using of the pervious concrete systems (PCS) is an effective method of the stormwater management at the urbanized catchments. The main hydraulic parameter in the drainage systems modeling is the stormwater hydrograph for the rainfall event of a certain intensity and duration. Stormwater management using the pervious concrete systems is sufficiently investigated novadays, but there are still some unsolved problems concerning the rainfall - runoff relationships, especially for the short-term rainfall events of the high intensity. A series of experimental studies of the stormwater outflow from the real PCS is performed in order to find the retention potential of the PCS for short-term rainfalls of different duration. The investigated sample of the PCS was installed in the experimental channel of the Laboratory of Hydraulics of LPNU. The dimensions of PCS are $3.0 \times 0.3 \times 0.32 \mathrm{~m}$. A typical construction of PCS used was as follows: bottom layer of the rubble stone with height of $0.22 \mathrm{~m}$ and top layer from the pervious concrete with height of $0.10 \mathrm{~m}$. Longitudinal slope is equal to 0.01 . The intensity of experimental rainfalls was equal to $103001 /(\mathrm{s} \times \mathrm{ha})$ and its duration changed in the range from $15 \mathrm{~s}$ to $60 \mathrm{~s}$. Special rainfall event with duration $t_{c o n}=38.4 \mathrm{~s}$ corresponds to the time of the runoff concentration from the analogical subcatchment without the PCS. Using of the PCS causes the decreasing of the maximum flow rate for this case in 3.1 times - from 0.927 l/s to 0.302 1/s, while the time of peak disharge increases by $20.3 \%$. Maximum flow rate and respective time of maximum outflow from the PCS were defined as the functions of rainfall duration. Experimental dependence between the rainfall duration $t_{r}$ and peak discharge time $t_{\max }$ can be satisfactory described by the exponential approximation $t_{\max }=27.5 \exp \left(0.013 t_{r}\right)$. If the rainfall duration is less than $60.0 \mathrm{~s}$, the maximum discharge of the outflow is observed after the rainfall event. If $t_{r} \geq 60.0 \mathrm{~s}$ the time of maximum outflow from PCS is simply equal to the rainfall duration, so as for usual impervious surfaces. Experimental time of the runoff concentration from the PCS $t_{c o n . P C S}=112.0 \mathrm{~s}$ is 2.92 times more comparing to the same impervious surface.

Keywords: pervious pavement; pervious concrete; stormwater hydrograph; maximum outflow; time of concentration. 